\title{
Editorische Zeichen
}

[...] Auslassung durch die Kommentatorin

[xyz] Ergänzung durch die Kommentatorin

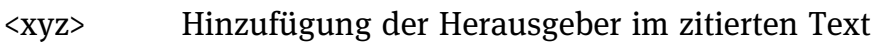

'xyz' Zusatz Nietzsches

xyz von Nietzsche durchgestrichener Text

/ Vers- oder Zeilenwechsel in einem Zitat

// Strophenwechsel in einem zitierten Gedicht

/Zahl/ Seitenwechsel in einem Zitat

- - - Bei Zitaten aus Manuskripten: Text bricht ab

[- - ] Bei Zitaten aus Manuskripten: unlesbare Wörter

$[+++]$ Bei Zitaten aus Manuskripten: Lücke im Text 
